\title{
ASTROS, METEOROS, ANIMALES Y PERSONAS: UNA APROXIMACIÓN AL IMAGINARIO Y VALORES KAWÉSQAR
}

ÁNGEL ACUÑA D. ${ }^{a}$

\section{RESUMEN}

En el presente trabajo intentaremos acceder a una parte del imaginario y valores kawésqar (pueblo fueguino del archipiélago patagónico chileno) a través de una muestra de seis cuentos tradicionales seleccionados de un repertorio total de 22, narrados por D. Francisco Arroyo y registrados personalmente durante el trabajo etnográfico realizado en Puerto Edén entre octubre de 2008 y febrero de 2009, y octubre-noviembre de 2010. Agrupados en tres categorías: 1. Astros y fenómenos meteorológicos; 2. Animales; 3. Personas; presentaremos el relato completo de cada uno de los cuentos elegidos, para analizar y reflexionar luego sobre los contenidos que se transmiten y las consecuencias que de ellos se desprenden. Finalmente, y a modo de síntesis, destacaremos las constantes más significativas del conjunto de relatos, como indicadores que nos aproximan al imaginario kawésqar y sus valores asociados.

PALABRAS CLAVE: Kawésqar, cuentos, mitos, valores, cultura.

\section{STARS, METEORS, ANIMALS AND PERSONS: AN APPROXIMATION TO THE KAWÉSQAR IMAGINARY AND VALUES}

\begin{abstract}
In the present text we will try to access to a part of the kawésqar imaginary and values (the kawésqar are a fuegian people of the Chilean Patagonian archipelago) using a sample of six selected folktales from a repertoire of 22, narrated by. D. Francisco Arroyo and personally registered during the ethnographic work completed in Puerto Edén between October, 2008 and February, 2009, and October-November, 2010. The folktales were grouped in three categories: 1 . Stars and meteorological phenomena; 2. Animals; 3. People. We will present the complete stories of the selected folktales in order to analyze and reflect on their content and implicated consequences. Finally, as a synthesis we will highlight the most significant constants observed in the collection, considered as indicators that bring us closer to the kawésqar imaginary and its associated values.
\end{abstract}

KEY WORDS: Kawésqar, tales, myths, values, culture. 


\section{INTRODUCCIÓN}

De acuerdo con Schwartz (2008, p. 27), la imaginación irrumpe en la percepción de la realidad y el mito en la visión del mundo, ensanchándose así el campo de lo posible. Además de entretener, como importante factor de supervivencia, la principal función del mito ha sido generalmente responder a las preguntas fundamentales de las personas en todos los pueblos y en todos los tiempos. Los mitos, las leyendas y los cuentos tradicionales populares expresan creencias y valores culturales. Ofrecen esperanza, emoción y evasión. También enseñan lecciones que la sociedad quiere enseñar (Kottak, 1996, p. 353). Asimismo, son capaces de generar juicios inmediatos sobre lo que está moralmente bien o mal en base a una gramática inconsciente de la acción (Hauser, 2008, p. 17). Transmitido de forma oral de generación en generación, aunque las versiones cambien y se multipliquen por el camino, la función permanece inalterable. Asimismo, quienes escuchan los relatos míticos suelen fundir temporalmente su individualidad en la comunidad de la que forman parte.

Lejos de ser entendido como ficción, dentro de la cultura que los produce, el mito, como señala Hocart (1985 [1969], p. 13), es fuente de vida, el precedente que sirve de referencia para interpretar o escapar de la realidad. No obstante, si bien es cierto que el mito describe el ritual y, por su parte, el ritual actualiza el mito (Hocart, 1985 [1969], p. 31), en el caso kawésqar (pueblo fueguino del archipiélago patagónico chileno) el esquema mitológico permanece aún vivo en la memoria de

1 Las mejores etnografías de los contemporáneos kawésqar del primer cuarto y de mediados del siglo XX han sido realizadas respectivamente por Gusinde (1991 [1974]) y Emperaire (1963). Desde los años 90 a la actualidad destaca el trabajo etnolingüístico de Aguilera (1995, 1997, 2001, 2007, 2011a, 2011b, 2013, 2016, 2017) y Aguilera \& Tonko (2005, 2006, 2009, 2010-2011a, 2010-2011b, 2013, 2017). Así como el aporte historiográfico de Martinic (2004) y Aguilera, N. (2013).

2 La Base de Datos de personas acreditadas como indígenas en 2008, elaborada por la CONADI en la Oficina de Asuntos Indígenas de Punta Arenas, reconocía 343 kawésqar en total (urbanos y autóctonos) (171 varones y 172 mujeres). En 2012, el total de acreditados como kawésqar por dicha Oficina era de 307 personas, y los residentes en Puerto Edén llegaban a ser solo 12.

Para el censo elaborado personalmente constituimos un algunos que son capaces de reproducirlo a través de los denominados "cuentos", pero no así el ritual que carece de vigencia actual.

Los kawésqar de hoy, aparte de los lazos consanguíneos con sus antepasados, distan mucho en cuanto al estilo de vida con los de hace apenas un siglo ${ }^{1}$ y más aún con los que avistó Jofré de Loaysa en el siglo XVI. Desde un punto de vista demográfico-estadístico la población kawésqar reconocida por el Estado chileno como "urbana" está repartida entre Punta Arenas, Puerto Natales y otros asentamientos menores. De acuerdo al censo elaborado personalmente en enero de 2009 sumaba 225 personas $^{2}$, mientras que la población residente en Puerto Edén, reconocida como "autóctona", al continuar habitando uno de sus asentamientos ancestrales, sumaba en esa fecha 20 personas (9 varones y 11 mujeres), de las cuales cuatro de ellas sobrepasaban los 70 años, según estimamos. Personas, estas últimas, que han sido testigos directos de un brusco proceso de asimilación cultural y experimentado en sus respectivas biografías un modo de vida seminómada adaptado a los recursos del mar.

Entre los actuales kawésqar, un hombre destaca por su conocimiento y memoria como narrador de cuentos: D. Francisco Arroyo (Paarte, nombre kawésqar, o Pancho, para las personas de confianza). Nació cerca del faro de San Pedro hace unos 70 años y por esa zona anduvo, o más bien navegó, durante su infancia y juventud, acompañado de sus padres y abuela; su único hermano murió siendo aún bebé. Más adelante sería con su padre con quien más relación tuvo, al

grupo de trabajo compuesto por seis kawésqar de Punta Arenas (cuatro mujeres y dos hombres de diferentes familias, entre las que se encontraba la Presidenta de la Asociación de Artesanos del Pueblo Kawésqar). Usamos como base de datos el mencionado censo oficial de 2008, en el que aparecía el nombre y apellidos de cada una de las personas registradas y su lugar de residencia. Lo revisamos pormenorizadamente en enero de 2009, detectándose que 12 personas del censo ya habían fallecido hacía años, 74 no se las reconocía kawésqar al no tener ningún lazo de filiación con el grupo y en 32 casos aparecían dudas, por lo que la cifra quedaba reducida a 225 kawésqar, la mayor parte de ellos residentes en Punta Arenas y Puerto Natales, seguido de Puerto Edén, y el resto dispersos por las comunas de Puerto Williams, Río Verde, Laguna Blanca, San Gregorio, Porvenir, Primavera y Timaukel. 
marcharse su madre con otro hombre. En 1969 llegó a Puerto Edén donde definitivamente se quedó, aunque tuvo ocasión de viajar y trabajar durante años en Guarello, dentro del archipiélago Madre de Dios. Tras el fallecimiento de su primera mujer se emparejó con una segunda que también murió, y sin haber dejado descendencia, desde hace años vive solo en su casa de la comunidad kawésqar en Puerto Edén.

Hombre callado, pensativo, tiene una peculiar manera de contar historias y un gran repertorio de cuentos tradicionales que aún recuerda haberlo escuchado de los mayores, sobre todo de su abuela y su padre en las largas noches. Como experimentado cuenta "cuentos", como él mismo los distingue, posee un estilo muy depurado cargado de dispositivos técnicos: con la mirada serena y orientada al frente habla con tranquilidad, a veces mira al interlocutor, sonríe, utiliza frecuentes y largas pausas, reflexiona, hace memoria, se interroga a sí mismo, siente el relato y se introduce dentro de él. De ese modo envuelve y atrapa la atención del oyente para que continuamente se sorprenda $\mathrm{y} / \mathrm{u}$ horrorice.

Su dicción en español resulta, sin embargo, algo dificultosa; para hablar mueve levemente el labio inferior mientras el superior queda inmóvil, sin llegar a cerrar del todo la boca; lo que unido a una sintaxis sui géneris, complica mucho seguir la comprensión del relato. Esta última dificultad se debe esencialmente a un problema de interferencia lingüística. El español hablado por los kawésqar de Puerto Edén sigue en la mayoría de los casos las estructuras propias de la lengua kawésqar, y ha sido recibido de la población chilota, distinto del de otras variantes dialectales del español de Chile.

Molesto por la, a su juicio, nula educación de los niños kawésqar en la actualidad, que influenciados por los hábitos chilotes interrumpen a los mayores y se rien de ellos, ha optado por no contarles los cuentos, circunstancia que muy probablemente haga que caigan en el olvido como tradición oral. Ante tal coyuntura, es el recurso escrito el que queda para asegurar su conservación ${ }^{3}$, la conservación de una forma de transmitir y adquirir conocimientos $y$ de pasar ratos entretenidos en las largas noches

3 Aguilera \& Tonko (2009, 2010-2011a, 2013) han sabido entender muy bien esta circunstancia y, dedicados con intensidad al estudio de la tradición oral kawésqar, están de invierno; de reunir información para entender mejor los acontecimientos y el mundo en donde se hallan inmersos; de compartir la experiencia de los antepasados y de los contemporáneos. En sus relatos se aprecia el detalle de las situaciones cotidianas relacionadas con la caza, la pesca, los viajes, la pernocta, etc., en solución de continuidad con las transformaciones que experimentan los personajes: personas convertidas en animales, en astros, o gente con forma animal; todo ello vivido con realismo al formar parte del tiempo primordial o fundacional. Es así como en el imaginario colectivo se percibe la existencia de la sol (con género femenino), la luna o las estrellas, el rayo o el viento; la vida del huemul, el sapo o el lobo marino; o la de sus propios congéneres.

D. Francisco, hombre experimentado en la práctica canoera, a pesar de que el paso de los años ha mermado sus cualidades físicas, mantiene intacta su memoria para relatar con gran maestría los cuentos tradicionales con los que acercarnos a una peculiar visión del mundo. Será él quien protagonice la narración de cuentos registrados en nuestro trabajo, y quien nos introduzca en el imaginario de su pueblo a través de los relatos que hacen familiares a los seres, animados o no, con los que han de compartir la existencia.

El objetivo central de este artículo es acceder a una parte del imaginario y valores kawésqar a través de una muestra de seis cuentos (que por razones de espacio no puede ser mayor) seleccionados de un repertorio total de 22, narrados por D. Francisco Arroyo y registrados personalmente durante el trabajo etnográfico realizado en Puerto Edén entre octubre de 2008 y febrero de 2009, y entre octubre y noviembre de 2010.

Desde el punto de vista metodológico, reunido a solas en el interior de la casa de $\mathrm{D}$. Francisco Arroyo durante días sucesivos, cuando el narrador disponía de tiempo y siempre en un ambiente distendido $y$ ameno, el investigador registró cada uno de los relatos que libremente se iban emitiendo, de acuerdo a la elección, inspiración e iniciativa del narrador. Todos ellos fueron relatados en español, por lo que no hubo necesidad de traducción, y posteriormente

ofreciendo en los últimos años una excelente producción científica a este respecto. 
transcritos de manera ortográfica respetando su literalidad. Seguidamente procedimos a ordenarlos según el tipo de personajes y temas o motivos que aparecían en escena; y clasificarlos de acuerdo a la naturaleza de los hechos narrados. Por último, llevamos a cabo el análisis de contenido de manera individualizada, relato por relato, prestando especial atención a las posibles interferencias o confusiones que se podían desprender del propio lenguaje; teniendo a la vez en cuenta el contexto histórico y sociocultural kawésqar en la interpretación de los acontecimientos que eran referidos.

Entre las formas de clasificar $\mathrm{u}$ ordenar los relatos mitológicos, algunas de las más comunes que podemos encontrar distinguen, por ejemplo, las que hablan de: la naturaleza, las relaciones de las personas con la naturaleza y las relaciones de las personas entre sí; o bien las que refieren: hechos maravillosos, animales y costumbres; aunque es normal que en cada relato haya en mayor o menor grado mezcla de todas estas categorías. En la tradición oral kawésqar, de acuerdo a la tipología establecida por Aguilera y Tonko (2006, 2009) y Aguilera (2011a), podemos distinguir dos formas básicas de acuerdo a la naturaleza de los hechos narrados: relatos de viaje y relatos míticos. Ambos tipos aparecen en el repertorio de relatos recogidos de D. Francisco Arroyo, que, en razón al personaje o motivo protagonista referido en cada caso, hemos agrupado aquí en tres categorías: 1 . relacionados con astros y fenómenos meteorológicos (maravillosos/de naturaleza); 2. referentes a animales (de animales/relaciones de personas con la naturaleza); 3. relativos a personas (de costumbres/ relaciones entre personas). De los seis ejemplos de muestra presentados aquí, los cuatro primeros son relatos míticos pertenecientes a las dos primeras categorías, mientras que en la tercera categoría encontramos un relato de viaje, $\mathrm{y}$ otro de viaje $\mathrm{y}$ mítico al mismo tiempo. En todos ellos el narrador de forma amena transmite un mensaje que conecta con la añorada tradición; una tradición que va desde la época fundacional o primigenia, en donde aparecen distintos episodios protagonizados por los antepasados más remotos, hasta épocas recientes, en donde se llama la atención sobre situaciones y anécdotas vividas por personajes aparentemente

4 Otros destacados autores que se pueden tener en cuenta para el estudio de la oralidad son: Hymes (1962), Finnegan históricos. Las implicaciones del mensaje, no obstante, son distintas, según la naturaleza del relato sea mítica o de viaje.

Consciente del sentido metafórico del cuento, lo cual hace necesario su no interpretación literal, así como el acercamiento a las costumbres y creencias del pueblo que las produce para su adecuada comprensión, la colección de relatos analizados parte de la lógica de lo concreto (LéviStrauss, 1987, p. 34), con situaciones y personajes claramente identificados en el tiempo y el espacio. Aunque, por otro lado, la diversidad de situaciones y actuaciones desarrolladas por los personajes se presenta a veces de manera imprecisa, no casual, ya que el mismo relator se interroga continuamente para encontrar respuestas al cómo, por qué o para qué ocurren ciertos acontecimientos en un mundo en donde el azar tiene difícil encaje. Por ende, no es un ejercicio de imaginación, sino de transmisión del conocimiento vía oral en una lengua ágrafa; forma de expresión bien estructurada y racionalizada desde la memoria narrativa.

Partiendo de la "teoría de los esquemas" (Casson, 1983) por la que se entiende que la mente constituye esquemas para filtrar nuevas experiencias y para reconstruir expresiones pasadas, modelando los recursos para adecuarlos a las expectativas presentes (Kottak, 1996, p. 370), lo cual deriva del "conexionismo" por el que los esquemas se desarrollan cuando un conjunto de experiencias vinculadas forman una red de asociaciones mentales fuertes (Ibid., 1996, p. 370), procuraremos contextualizar en la medida de lo posible los relatos escuchados en el ámbito sociocultural del que parten para interpretar desde fuera el imaginario y valores que de ellos se desprenden.

Siguiendo en parte la propuesta de Propp (1985 [1928], pp. 34-35), en relación con el análisis de los cuentos, aplicamos aquí un procedimiento deductivo que va del corpus a las conclusiones, tras haber observado la sucesión temporal de las acciones y los papeles que representan los personajes que aparecen, a fin de encontrar o comprender el sentido o sentidos que posee cada relato ${ }^{4}$. No obstante, como bien indica Aguilera (2011a) sobre la dificultad de seguir el hilo conductor de los participantes en las narraciones

(1970), Eco (1977), Todorov (1978), Kristeva (1978), Ong (1982) y Tedlock (1983), entre otros. 
kawésqar (ya sea en lengua nativa o en español kawésqar), muchas veces es difícil establecer la referencia ¿de quién se habla?, ¿quién habla? o ¿quién hizo qué a quién?

Para el no hablante de la lengua resulta enigmático determinar cuál es el participante en la narración al cual se refiere el hablante en los siguientes casos: (1) la referencia apunta a factores culturales (es propio que la persona referida sea quien ejecute ciertas tareas o funciones específicas dentro del grupo que son muy claras para los miembros del mismo y, por lo tanto, no es necesario nombrarla); (2) en ocasiones la distancia referencial es grande $y$ se remonta a varias oraciones anteriores; (3) el poco uso de pronombres; (4) el uso abundante de referencia $\varnothing$ (referencia nula); (5) la falta de diferenciación de género en las formas pronominales produce "interferencia" en la localización del referido cuando se combina con (1) y (2); (6) la no inclusión de un pluralizador verbal optativo que puede hacer ambiguo el número y (7) error del narrador al no especificar claramente la referencia, esto debido a que hizo un paréntesis en la narración a fin de describir algo y luego retomó la narración aludiendo a una persona mencionada antes, pero cuya distancia referencial se hizo extensa, sin percatarse de este hecho (pp. 129-130).

5 El corpus total de 22 cuentos, en función de su contenido y de las figuras o personajes principales que lo protagonizan, está ordenado en tres categorías: 1. Sobre Astros y Meteoros: Cuento de la Sol la Luna y las Estrellas; del Arcoíris; del Rayo; de la Tormenta y la Noche; del Viento. 2. Sobre Animales: Cuento de la nutria y el huemul; del Ratón; del Sapo; del Perro (1); del Perro (2); del Lobo Marino; del Pato Lile; del Pajarito Wasana; del Pájaro Carpintero; de la bandá de Quetro. 3. Sobre Personas: Cuento del Cazador de Lobo Marino; de los dos Hermanos en Calcetín; del Kawésqar que cuidaba papas silvestres; de Kecheskula; de los compañeros de viaje por Madre de Dios; de Enfrentamiento y Ayuda mutua; del Hombre Flojo.

6 La transcripción literal acerca al lector la forma en que fue expresado el relato en español hablado por kawésqar, aunque dificulta su comprensión por no coincidir exactamente con la sintaxis habitual del español normalizado. La falta de género en kawésqar es un factor que puede producir
Sin olvidar las acertadas observaciones de Aguilera, a fin de facilitar el análisis de los seis cuentos sustraídos del corpus total de $22^{5}$, los presentaremos a continuación agrupados bajo las tres categorías ya citadas, a razón de dos cuentos representativos por categoría. Transcribiremos en primer lugar su contenido de manera ortográfica, tratando de reproducir el habla del informante sin alteración alguna ${ }^{6}$, aunque descompuestos en unidades de significado, para analizarlos seguidamente, reflexionar sobre los posibles mensajes que transmiten y las consecuencias que de ellos se desprenden ${ }^{7}$. Finalmente, y a modo de sintesis, destacaremos las constantes más significativas del conjunto de relatos, como indicadores que marcan el imaginario kawésqar y sus valores asociados.

\section{ASTROS Y FENÓMENOS METEOROLÓGICOS}

\section{La Sol, la Luna y las Estrellas (relato mítico)}

1. Ese sol questá lumbrando ahora ese fue una persona, fue una señora, tenía como sinco, sei hija, puro hija de mujer.

2. Despué hiso que su hija que tenía fueron parriba pal sielo;

3. no sé como sería el cuento que me contaba ante,

4. lo pusieron una vara, una fiska donde que sacaba cholga o eriso, eso lo paró parriba pa que su hija, entonse subió parriba to eso, to eso mujer.

5. Primero subieron sol, y la luna

confusión; así como la ergatividad kawésqar al expresarse en español puede hacer que se malinterprete algún enunciado. Por otro lado, al comparar alguno de los relatos registrados por el autor con otros de semejante título (como el de la sol, la luna y las estrellas, el pájaro carpintero, o el del arcoíris) registrados en la literatura (Aguilera \& Tonko, 2013), apreciamos por su extensión que los primeros pueden ser una versión reducida de los segundos.

7 Conscientes de los posibles errores de interpretación en que podamos incurrir al descifrar las palabras literales del narrador, el lector siempre dispondrá aquí de los textos originales de los cuentos que han sido utilizados como soporte, a fin de poder descifrar él mismo la posible intencionalidad que de ellos se desprende, y si lo desea, contrastarlos con otros textos de cuentos kawésqar publicados por otros autores (Aguilera \& Tonko, 2009, 2010-2011a, 2013; Aguilera, 2013). 
que está en la noche, eso igual era mujer, después su hermana mayor, la luna que sale en la noche,

6. esa no tenía ni hijo ni hija, ella sola na má subió parriba,

7. y a lotro día no sé cómo sería, uno, do, tre día má sería que se pareció arriba el sielo otra ve que, que venía buscar su hermana pa que vaya parriba el sielo;

8. entonse ella lo llamaron que se salga fuera pa que, pa que suba parriba con su hija que tiene to, tenía quí, que no deje ninguno ahí;

9. entonse esa mujer no quería, no quería subir parriba porque dise que lo pensaba mucho, no, "¿cómo vamo estar arriba?” pensaba, “¿qué cosa puede ser arriba, puede ser bueno o, puede ser un lugar bueno como acá sería, habrá mal?"

10. Y lo preguntó parriba "¿qué cosa bueno hay parriba, hay alguna cosa, el mundo sería como acá bajo?”, preguntaron;

11. "sí, si son lo mismo questánabajo, más mejor questán ustede ahí, má mejor acá arriba, hay loco, hay eriso, hay maucho, hay to hay pa comer, dijo, hay tremendo loco, maucho, lapa, to eso, tremendo lapa, loco, maucho";

12. ya, po, si la mujer questaba abajo la pidieron, po la quiere uno por marisco, "que tire loco pabajo y eriso igual tiene que tirarle pa bajo, y maucho y lapa, a ver si e cierto"; entonse lo tiró.

13. Claro estaba arriba lotra mujer su hermana; "ahí pa que lo vea te voy tirá pabajo unos cuanto, po, marisco na má e que lo tiró pabajo;

14. TREMENDO marisco, eriso, loco, to eso grande, arriba dijeron que era chiquitito, "eso es lo mas chico que lo recogí, no es grande eso"; "pero cómo allá va ser má grande”, claro, ahí se pensó.

15. "Parée que me voy parriba", dijeron ella, "que voy a ir parriba mañana en la mañana me viene a buscar", dijo, temprano, la hora que manesió, resién no.

16. Poreso quelsol sale en la mañana, a esa hora subió parriba, el día clareando, sus chica quearon to ahí, subió a puro su mamá.

17. Despué a la tarde oscuresiendo vinieron a buscar, tenía que irse to pa rriba, tenía que saber má luego como a media noche subir to pa rriba un viaje, to junto, tenía quesperar la hora que iban a subir;

18. claro subió uno por uno, ya subieron to parriba, ya no hay ma eso gente del mujere, el resto lo compañero quearon to ahi solo;

19. ahi está lotra mujer, to, quearon unos cuanto hombre ahi cuanto hombre queó;

20. pensaron éste "¿pa qué lo llevarían a to parriba?", dijeron lotro, "éste ya no vienen má, ya subieron to parriba".

21. Despué se hiso luna, sol na má, las chica que subieron to se volvió lastrella, to esa puro estrella, ese fue las chica que subieron to.

22. Entonse eso era muy lindo cuento eso, los antiguo dicen que serca el sielo pa subir, que alcansaba vara hasta arriba.

23. Que esa mujer, la luna que sale de noche, ese se partió la vista, se reventó, no sé que habría pasao ahí, que senojaron con su mario, no quiere que come eriso, agarró eriso, lo plantó garrotaso con palo, se llenó laspina y quearon sin la vista despué, tenía ojo un solo lao.

24. No sé qué cosa habría varao, una cosa lobo o tonina, no sé qué sería eso, eso igual comía eso, ca uno se mariscaba pahí y varao to eso animale lobito del mar;

25. entonse ca uno tenía que quitarle to eso carne pa comé, coneso mantenía lo que lo mataba arriba la luna, dise que queaba esa cuestión.

En este relato los astros son presentados como personas femeninas, incluido el sol. Personas que vivían originariamente en la tierra y la curiosidad y el descubrimiento de horizontes más prósperos hizo que subieran arriba para finalmente quedarse. 
La luna fue quien subió en primer lugar por medio de una fisga (vara larga para capturar marisco del fondo del mar) y convenció a su hermana mayor: la mujer sol, para que también lo hiciera, al comprobar que había buena comida, al igual que en la tierra (marisco, lobo, etc.), con la diferencia de ser de mayor tamaño. El asombro y la admiración de la hermana sol, impresionada por esta circunstancia, fueron decisivos para hacerla cambiar de opinión y vencer su inicial desconfianza.

Tras haber subido al cielo al amanecer del siguiente día, como prometió a su hermana que la fue a buscar, y comprobado las óptimas condiciones que reunía para trasladarse a vivir en él, ambas hermanas (luna y sol) bajaron de nuevo al atardecer para hacer subir a las cinco o seis hijas de mamá sol que habían quedado en tierra, cosa que hicieron a media noche convirtiéndose éstas en estrellas. Los humanos quedaron abajo, contrariados por el abandono y la imposibilidad de volver a estar reunidos con sus antiguas compañeras, ahora convertidas en astros.

Ya en el espacio celeste, la luna perdió la visión de un ojo al clavársele una espina, producida por los garrotazos que su marido propinó a los erizos que pretendía comer. Cada cual comía la carne de los animales que podían y quedaban varados: lobos marinos, toninas, ... ${ }^{8}$

Como se observa en el relato original, el narrador insiste mucho en la desconfianza de la mujer sol para subir a un lugar desconocido, y en el valor de la comida como incentivo fundamental para conducir a las personas. El enorme tamaño que para los habitantes de la tierra tienen los productos del mar que son normales en el cielo evoca la idea de abundancia y prosperidad, aspecto que en el presente relato se limita a los

8 Éste, como otros cuentos, tiene varias versiones, y faltan episodios para completar la narración en toda su extensión. En otra versión, el episodio de los erizos es previo a la subida al cielo. De los distintos fragmentos podemos establecer que el cuento tiene una parte en la cual se narra la vida terrenal de las hermanas. Como existen varias versiones, muchas veces encontramos datos contradictorios, por ejemplo, en una versión la mujer-sol asciende primero, en otra, la mujerluna. El propio narrador reconoce aquí que no conoce bien el cuento "3. no sé como sería el cuento que me contaba ante". En la versión registrada por Aguilera \& Tonko (2017, pp. 40-43) sobre Cuento de los astros, narrado alimentos pero que en otros similares (Aguilera, 1995; Aguilera \& Tonko, 2013) se refleja en la existencia de un ambiente cálido y buen tiempo meteorológico, o de jóvenes apuestos y atractivos para las mujeres astros. También la prudencia de la mujer sol es un factor sobresaliente, al ir solo acompañada de sus hijas cuando comprueba que en el otro lugar hay buenas condiciones de vida. Rasgos todos ellos muy propios del modo de ser atribuido a los antepasados kawésqar, que evitaban en lo posible aventuras en el mar (su mundo conocido) sin que se dieran unas mínimas condiciones meteorológicas, y tenían en la existencia de alimentos un motivo esencial para cambiar de residencia.

Resulta sugerente la transformación que experimentan los protagonistas del relato, que son originariamente personas y se convierten en astros al pasar de abajo a arriba, así como la asociación con lo femenino, ya que en todos los casos se habla de mujeres, circunstancia ésta inusual en la mitología de otros pueblos sobre tales figuras, en donde resulta más frecuente encontrar lo femenino y lo masculino de manera complementaria. Especialmente significativo es el papel que cumple la mujer y mamá sol (desconfiada y prudente), protectora de su prole (las estrellas). Papel por tanto esencial, asociado a un astro (o habría que decir "a una astro") que cuida la vida de todos por el calor y luz que aporta, luz y calor que son especialmente gratificantes en un territorio (canales patagónicos) donde escasean.

Igualmente revelador es el hecho de que sea el amanecer cuando mamá sol emprende su subida al cielo, y sus hijas las estrellas lo hagan a media noche, momentos ambos en los cuales realmente se hacen visibles tales astros.

en kawésqar por Francisco Arroyo, el mismo narrador de las versiones en español que aparecen en este artículo, la disputa por los erizos se da por los celos de la mujer-luna y aprovecha la ocasión en que el huairavo, el marido, quiere comer erizos, ella le golpea la mano con un palo y se pincha con las espinas del erizo y algunas se le incrustan en la mano. Posteriormente la mujer-luna se pincha un ojo con una espina cuando un animal de gran volumen vara en la playa donde ella se encontraba (en otra versión del cuento). Es probable también que se pinchara con las espinas del calafate, pero no se señala en las versiones. Después de este evento ella decide subir al cielo. 
El viento (relato mítico) remolino.

1. Hay viento fuerte que hase como

2. El viento que había una parte atrá del puerto, canal Picton, porahi, en la isla que había allá, es lindo playa ahí, mirando pa juera (fuera) pal ueste, ahí dise que había uno deso,

3. en la playa, en el mar salia, hay una hombre que habia la sintura alagua dise qe había, de eso que hase viento;

4. tal como estamo hablando, del bosque sale como remolino, como viento,

5. entonse patrá hay una carpa antigua que loja siempre a lo gente, ahí pasaba, lo farataba su carpa, lo plastaba humo pa entro, losfixiaba con mismo humo toa la gente, lluvia, temporal, marea baja merma, no baja;

6. ya lotro questá ahí cabreao, no sé por qué no baja marea, calma viento, to lo día amanesía viento, lo pensaba ahí,

7. "¿ónde vendrá tanto viento que nunca calma aquî?”.

8. Na que el viento salía atrá, atrá de ello, ahi, está lejo del viento que viene;

9. entonse uno dise que fueron casar quetro porahi, a mirá, porahi poronde está la playa ahí pasó mirar, ahi había unhombre o una mujer, dise questaba alagua, lo pegaba su mujer, ese dise que lo hasia viento ahi, tremendo viento a racha;

10. y ahí lo vieron ahi y fueron pal carpa lotro, "oye éste parese questá hasiendo viento lo pensé", hablaba solo ahi, me cago, una persona pareció, una persona questaba alagua, cómo no tendrá frío, a lo mejor eso sería el viento, cómo se malea el tiempo eso;

11. claro, si llegó su carpa, se llegó, cansao se extendió al rato ahi, "bueno iputa!, que me cansé tanto caminar, no había ni una cosa patrá, nose veía quetro, na", cabreao aguaitando (mirando) quetro.

12. El viento ese a racha no deja el viento del mar; de ahi dise que preguntó uno conotro: "oiga usted sabe ahí atrá qué hay"; to cabreao caminando;

13. lotro dise que no, "si no, nunca ha andao lejo";

14. claro, lo pensaron algo lotro, cabreao lo vio elotro cómo está preguntando.

15. Ya dijeron que hay una cosa linda playita questá ahí arriba, ahí salía viento, ahí mismo parriba;

16. claro, salía tremenda racha porahi parriba, ya pa juera no había viento na, ya miraba parriba lalto, se veía, iputa!, calmita se veía lotro lao;

17. dijo: "paree quel viento sería aquí no má”, dijo;

18. claro, "paree igual que una persona que se había igual que sea viento, había una mujer, un hombre, iputa!, vamo mirale no má, vamo too";

19. "hay que llevale alguna cosa", claro, ahí estaba, ahí lo aguaitó;

20. "vamos a ve lo que estaban ante ahí arriba, vamo mirá".

21. "Claro, ahí está eso que vimo endenante, era paresio una persona pero hase viento ese; claro, ese son que soplaba".

22. Despué dise que lo mataron, no sé como fue, y ahí calmó eso; claro, to el mes, to el año ahi, no hay más viento.

23. Claro, ese era quien hasía viento, cuando manesió calma lotro día; manesió calma, bajó marea, to eso; ya no es na como primero questaba malo.

24. Agarrao a sargaso ese hombre estaba, volaba sargaso parriba, hasta el mar hasia volar hasta arriba el monte; era pura racha ese remolino del mar.

25. Ese era el cuento antiguo.

26. Es peligroso pa canoa eso, pue volcar, se llama sæfkás qálksta (soplar el viento), se llama ese, pue echar a pique la canoa.

En síntesis, este relato del viento es localizado en el canal Picton. Quienes sienten sus molestias se interrogan ¿de dónde vendrá? y observan que a modo de remolino sale del bosque, junto a la playa situada en una isla. También aprecian junto a ese lugar a un hombre y a una mujer introducidos dentro del mar, con el agua 
por la cintura, mientras él golpea a ella (cabe interpretar). Sin haber resuelto la incógnita, se sorprenden que la persona no tenga frío dentro del agua, y observan que el viento se produce tan solo en ese lugar, ya que hacia afuera el tiempo está en calma. Prestando más atención se dan cuenta que lo que en un principio identificaban como una persona (hombre) y ahora matizan como un ser parecido a una persona, es quien lo produce al soplar. Convencidos de ello decidieron acabar con él, aunque no se sabe cómo, y comprobaron que, en efecto era quien lo originaba, al cesar de soplar y quedar todo en calma tras su muerte.

El relato nos desvela por un lado el origen o la causa del fenómeno en cuestión, vinculado a un ser no humano que con forma de persona, de manera deliberada, lo genera mediante su soplo9. Por otro lado asocia el efecto del viento con aspectos negativos: destruye las viviendas o carpas; hace que el humo de su interior no salga bien y provoque asfixia en quienes se encuentran dentro; ahuyenta a las aves e impide que los hombres puedan cazar, en este caso patos quetros; impide que baje la marea para poder mariscar; provoca un elevado riesgo en la navegación con canoa al hacer que éstas puedan volcar e irse a pique; y asociando la figura de la mujer que aparece metida en el mar con el agua por la cintura, con las posibles mujeres que salen a mariscar a diario, el fuerte viento las azota o castiga en el ejercicio de esa cotidiana tarea. El viento, en definitiva, cuando es fuerte y no cesa, produce molestia, enojo, mal humor (cabreo) a los kawésqar, por las negativas consecuencias que trae consigo; sin embargo, y a pesar de que quien lo causa es un ser poderoso supuestamente maligno que está más allá de lo humano, la actitud de quienes lo padecen no es de resignación sino de decidida intención de ir contra él y darle muerte para acabar con el problema ${ }^{10}$. Actitud nada dialogante o conciliadora en este caso, al no producirse negociación alguna para que amaine; pero valiente y nada conformista, al optar por matar como solución, sin reparar que uno puede también ser muerto en el intento.

9 En otros casos registrados en la literatura se dice que lo origina un ser no humano al golpear el mar con una vara (Aguilera \& Tonko, 2009, 2013).

10 En el conjunto de 22 cuentos que forman el corpus total de relatos registrados, donde aparecen situaciones indeseadas,

\section{ANIMALES}

La nutria y el huemul (relato mítico)

1. Ese dise que no era igual gente, huemul no má.

2. Dise que lo trajeron juego (fuego) el huemul, trajo juego;

3. ante se partió el mundo que iba a pique to.

4. Los kawésqar antiguo dise que arrancó parriba punta cierro porahi, a pinar dise que salvó los restos to partio,

5. cayeron to la costa, partió canoa, too se partieron ahi porque ello se salvó los do no má, los do o los tre, parese que salvó, el matrimonio salvó justo su familia de los tre familia, su hijo, su hija, paree queran cuatro por to, y su mujer delhombre que vivía conella.

6. Siguió lo cierro parriba pa que no lo pille el temporal del mar que viene hasta que llegó arriba, y a la orilla de donde está sentao porahi dise que tremendo rellenao ahi;

7. a pinar dise que una islita chica, estuvo una hora, dos hora, despué se pensó bajar otra ve, a poco bajando bajando queó otra ve pa el cierro.

8. El costa ese que ahí lo peló tó, salieron toa la rama, el palo to ese rancaron caeron to con corriente.

9. Entonse ese hombre que se fue corriendo arriba pa salvar ese no vio ni una cosa, no vió su fósforo que usó,

10. lo pensao qué cosa vamo haser ahora pahaser juego (fuego) pa alguna cosa, está soleao por estar bien marea que baje, vamo a volver pabajo, con qué vamo comer.

11. Claro que se bajó marea ya no lo voy trincar otra ve, y al paso dise que bajó pabajo;

12. entonse ahi dise que llegó pa dejar juego (fuego), se lo vio una cuestión

molestas o peligrosas provocadas por los propios congéneres o por seres no humanos aparentemente malignos, a la opción de matar, que se presenta con frecuencia, se le une también la de expulsar del lugar a los causantes del problema. 
medio rojo,

13. pasó mirar dentro carpita, una carpita con la rama tapao questánahí paentro y entro ahí,

14. era huemul questaba parao mirando que tenía su juego (fuego),

15. entonse ahí se caeron, miró patrá se movió su cabeza ahí cayeron peaso tisón, elotro dise que lo agarró ahí pa que no pague;

16. claro, conese ese juego ya dio juego, lo contraron palito seco partío y desapareció los huemule-s (el huemul) que andaba dentro carpa,

17. ya no sabía ná, nada má que dejar juego sería nada má, y ahí conese se bajó pa bajo,

18. ya no, ya lotro liso (lo hizo) un canasto paguantar juego, puso el barro abajo y coneso bajó pabajo, ahí quearon otra ve.

19. Es que ello-s fueron a buscar lobo a pesca, tenía una cueva lobo, una caverna lobo que hay ahi paentro, una colonia lobo hay y lo pasaba buscar siempre dise que buscaba;

20. elotro cabro, cabrito chico desía que está gritando su hermana avisar su papá, su mamá, questán cargando lobo ahi.

21. Ese fue kawésqar antiguo, cuento antiguo que viene de San Pedro porahi,

22. ese fue que maleó tiempo, había una nutria que no podía matale que se llevaba mal tiempo ahi;

23. ese llegó, lo mataron ahí, se fueron avisar los cabrito que sabian eso, "no lo mate esa nutria dise que le preguntó elotro", dijeron que no lo mate porque se malea tiempo conese, que se iba maleá tiempo por matale pa comele,

24. mejor había matao dentro una posita llena río está lindo lugar ahi, conese dise que se iba levantar malo, tremenda lluvia, temporal, relámpago, to eso, se

11 En las versiones de este cuento narradas por Francisco Arroyo en kawésqar y ofrecidas por Aguilera \& Brito (1980, pp. 309-316) y Aguilera (2013, pp. 213-215, 217 - maleó el tiempo y ya no,

25. mató nutria y se murió, cayó en la costa ya murió, ya no, murieron to questaba ahi,

26. ese fue que vinieron avisar cabrito, eso es algo que ello sabía to eso lo que, lo que estaba ahi sabia, los que vinieron otro año no saben ná,

27. está bién questá hasiendo cabrito pero no lo tomaron cuenta questaba hasiendo na ni una cosa, se pensarán questá guaeando (hueviando = molestando) na má, era sierto.

28. Ahi fue que se rrancó al tiro, salvó ese cabrito,

29. lo que vinieron dotro lao se muriero to, no queó ninguno, qué iba saber que iba subir hasta arriba el cierro, ya parriba ya no crese, (...)

30. Ese es porahi Natale, afuera Natale pa juera, ese no es cuento pacá serca o parriba [echa agua en el mate].

El relato posee dos protagonistas que aparecen por motivos diferentes en dos partes diferenciadas de la narración, que por este orden son: el huemul en relación con el fuego y la nutria tabú cuya muerte produce una gran marejada. El orden de la narración, sin embargo, aunque en este caso fue contada así, por su contenido bien pudiera invertirse, al aparecer la segunda parte como una aclaración de lo ocurrido en la primera: comienza relatando acontecimientos cuyas causas son explicadas con posterioridad. En la narración se puede apreciar una cierta confusión en cuanto a la procedencia o lugar de los hechos, ya que al principio se ubica por la zona del faro de San Pedro (al norte) (4741'S - 7454'O aprox.) y al final se sitúa en la zona de Puerto Natales (al sur) (5143'10"S - 72³1'0”O). No obstante, podemos entender que la gente que mató a la nutria procedía del faro de San Pedro y los acontecimientos ocurrieron en Puerto Natales.

En cualquier caso, el relato explica en primer lugar cómo una familia kawésqar ${ }^{11}$ integrada por dos o tres personas (matrimonio junto con hijo

221), solo se salva una pareja, un hombre y una mujer. En una de esas versiones se dice además que eran enamorados y el joven mató a la nutria tabú. 
o hija), se salvó de un devastador temporal con alta marejada, al subir a un gran cerro cuando el mundo "se partió" y acabó con todos. Cuando llegó la calma uno bajó y comprobó la dimensión del desastre, mientras arriba estaban desolados al no tener fuego para preparar alimentos.

En la costa vieron humear una carpa y en su interior encontraron el huemul con su fuego. De ahí recogieron un tizón y con palitos hicieron también fuego para ellos. El huemul (que en este caso no era persona) se fue, desapareció, y toda la familia bajó a la costa donde se instaló y fabricó un cesto con barro en la base para transportar el fuego.

A partir de aquí, se advierte un cambio narrativo, manteniendo nominalmente a los personajes, para relatar lo que entendemos era la justificación de la catástrofe inicial. De este modo cuenta que la familia al salir de caza con la intención de capturar lobo marino, vio una nutria y decidió no matarla al considerar que si lo hacía se levantaría el temporal con lluvia y relámpago. Los del lugar lo sabían, pero la gente venida de fuera, de la zona de San Pedro (territorio Sælam), lo desconocía y la mató. En consecuencia, el tiempo se maleó y murieron todos con el temporal generado, salvo la familia que, a diferencia del resto, falto de conocimiento, subió al cerro para salvarse (final éste que coincide con el principio del relato).

De acuerdo a cómo fue contado, en la primera parte describe cómo la existencia del fuego, recurso de enorme importancia, se le debe al huemul que amablemente lo cedió. No obstante, no pasa desapercibido el hecho de conseguirlo tras haber pasado un tiempo de apocalipsis, de destrucción, por el que quedan en una situación de supervivencia, en la que el fuego figura como elemento salvador, al igual que el monte donde se protegieron del temporal. Esta parte del relato es muy semejante a otros muchos relatos existentes en pueblos amerindios distantes que tienen que ver con la idea del diluvio o la gran inundación por la que unos pocos seres humanos se salvan, habitualmente subiendo a un alto cerro de la zona.

12 Como apreciación de los evaluadores de este artículo, la nutria en sí misma no es percibida por los kawésqar como un animal sagrado; pero la del relato, en particular, pudiera habitar en algún momento un lugar sagrado, o estar criando, en cuyo caso ha de ser respetada para lograr la
Tras esta primera parte que habla del origen del fuego, la segunda (que cronológicamente tendría que ser la primera) es, como suele ocurrir en otros cuentos, instructiva y nos avisa de lo que puede suceder cuando se viola un tabú, como en este caso es matar una nutria. Animal que, aunque presentado aquí como intocable, en la vida cotidiana y en la historia contemporánea kawésqar ha sido perseguido y cazado por la piel con la que se comerciaba. No tenemos noticias que se trate de un animal sagrado, aunque habría que ver si la del relato es de algún tipo especial (la madre o la protectora de todas las nutrias, tal vez $)^{12}$.

En otros pueblos amerindios (Yanomami, Yukpa, etc.) está permitido cazar distintos tipos de animales (lapa, picure, pava de monte, venado, etc.), pero está prohibido matar a aquellos que son únicos y se consideran los progenitores, dueños y espíritus tutelares de cada una de las especies, a riesgo de sufrir diversas calamidades o infortunios que son interpretados por violar el tabú.

En cualquier caso, lo más importante es observar cómo el mal tiempo, el temporal, se atribuye al incumplimiento de una norma obligatoria, y son los de fuera, los incautos que no saben, los que las incumplen por desconocimiento y los responsables de generar peores condiciones para vivir. Por lo demás, no pasa desapercibido el hecho de que el temporal, caracterizado por las tormentas y la marejada, lo asocian a la muerte indebida de un animal que hace su vida en el agua. En definitiva, la causa se debe a la ruptura del tabú.

\section{El ratón (relato mítico)}

1. Ese estaba allá abajo, por Trinidá dise questoy ese ratón,

2. ese fue hombre, hombre que lo dejaron solo,

3. su mamá lo embarcó lotro kawésqar lo llevó payá parriba, por San Pedro, porahi estuvieron año, como 10, 20 año sería questuvo ahi conotro hombre y ahi se pensó su hijo porque lo dejamo pabajo eso año;

supervivencia de sus crías, que son animales útiles para la caza. En tiempos antiguos su piel se usaba de vestimenta y luego pasó a ser pieza de caza para comercio con los loberos y nutrieros blancos. 
4. a lo mejor se moría alguna cosa, capá-s (capáz) se vivió costareando como hombre viejo to esos año;

5. entonse elotro dijo: "vamos a velo", elotro fue que le tocó buscar parriba;

6. dise que alguno dise que es malo, $y$ desía que venía matar al ratón dise que venía matar ahi,

7. que lo maten fueron pabajo, pero al ratón no pué matale porque ese es muy rápido pa correr, pa efender si tira piedra cualquier cosa no no llega a su cuerpo ante que pase alguna cosa piedra o la flecha dise que saltaba payá, ahí no lo pillaba na, y algún del garrote pa pegale igual tampoco no lo pegaba,

8. entonse elhombre que viniera lo mataba entre ello pa que mate al ratón, el ratón no lo mataba porque varia gente lorganizó que lo mate eso;

9. entonse eso fue que lo pensó su mamá, a ver mi hijo que está gueando (hueveando $=$ diciendo tonterías) porahi, cómo tanto guaeao (hueveo) conesa gente rareao malo;

10. cómo sería cuando llega gente, cómo lo resolverá, ya no tenía confianza pa estar la vista ello-s el ratón,

11. tenía quesconderse al tiro na má porque ya sabe que venían matar ello-s;

12. a lo mejor viene muy pa aguaitar (ver) nosotro, "ya viene matarme a lo mejor, poreso viene";

13. miraba parriba al cierro, bien alto cierro como eso questán allá alotro lao porahi parriba porahi dise que miraba, porahi viene eso que viene aguaitar nosotro.

14. Soy lejo, hay una embarcación que viene bajando pabajo;

15. entonse tanto que conversaba que había un cabrito chico, bien chiquitito, toavía no pué matale dise que no; braseó";

16. "vamos a vele pa lo mejor se

17. claro, fueron ahi pabajo pa mirale, ya tiene su hermanito igual lo llevaron pabajo;

18. enelotro cabro, llegó donde que estuvieron ya sabía que vivía ahi enese porto (puerto);

19. "claro, ese tiene que ser mi hijo, como estaba aqui el porto que estamo antes", dijo,

20. entonse ya dise que lo gritó porque no te voy matá porque yo soy tu mamá.

21. Ya lo pensó to, lo quebró to, la pala, el remo lo quebraba a pedraso ahí.

22. De tanto guear (huevear) dise questaba enojao ese hombre, ya se salió a tierra, ahí lo preguntó, habló conél, ya le dijeron questuvieron ahi elhombre, elotro hombre dise que lo pasó llevar el cabrito ese que loscondió pabajo rama ahi, quearon botao ahí solito,

23. (...) queó solo no sentía ninguna cosa, caminar gente no sentía na, dise que miró por to lao, estaba toa su familia muerto, tirao porahi camino elotro pabajo, parriba, to eso tirao ya.

24. Ca cabrito dise que pensó: "ahora qué vamo haser, queamo solito, mi mamá, quién sabe poronde estaría ahora no sé ná, mi papá está muerto, mi tío to está muerto, ahora qué cosa puede ser ahora, estamos solo, y ahi está su canoíta, lo dejaron su canoíta pa que ande ahi, conese tenía que andā".

25. Yampesó trabajar parreglar alguna cosa, arregló su fiska pa sacar eriso, pa sacar cholga, pa sacar alguna cosa sacá coneso,

26. arreglar arpone su lancha pa cualquiera cosa, tonina o lobo que pase porahi enese pase angosto que hay, o pájaro, lile, to eso, el pato quetro igual que casaba,

27. ese quera bueno pa casar ese ratón, caminao lejo porahi, dise que andaba porotro lao porahi, la isla Mare e Dio porahi dise que caminao crusaba con palo, ante que se desarme palo dise questaba lotro lao;

28. cómo fue dejaba tormenta canal y ahi volvía coger alotro palo conese llegaba a lotro lao ante que salía ahi;

29. elúltimo que queó ratón no má, 
ya terminó lhombre questuvieron,

30. elotro nosé cómo fue eso, elúnico que me contaba es que estaba arriba el cierro (cerro) to eso parriba, a mirar lejo,

31. dise que tenía tremenda carpa ahí, tapao con peaso alguna cosa o palo, lo sería algún algún cabeza lobo, tonina parese que fue el cuento que contaba, tapao de cuero de nutria, cuero de lobo fino será eso, porahi paréh (parece que) lobo fino, dise que hablao con mismo que tenía tapao;

32. cuando viene lotra gente afuera es questá tapando a gente dentro carpa, porque levanta mirando lejo él solo,

33. pa mirá que venía gente de fuera aguaitar lo está puchando, está guaiando (hueveando) no má lo vió ya, ya lo tiró de lansa pa entro, pa matale pasó clavar en tierra;

34. dise questaba ahí tranquilo hasiendo su lansa ratón y ahí dise que lo miraba questaba hasiendo tremenda lansa que sale, to parese que no es trabajo mio [se sonrie].

35. “¿Cómo diablo se pareció lansa pacá?", "nosotro estamo hasiendo lansa bien chiquitita, tremendo arpón clavao tierra acá, no estamo acá hasiendo nada, puro lansa asesinar";

36. ya llegó clavar elotro llega su cuerpo, ya dise que ha rancao pal monte porahi, se bajó pa bajo, sembarcó dentro canoa, porahi anda,

37. ya lo tirao piedra, palo, cuidale ni una cosa, dise que lo dejao una, dos persona pa que se vaya parriba otra ve, pa que venga lotro, ya fueron parriba,

38. ya con to su familiar empesó conversar lo mataron to lo que venimo, al final nosotros venimo solo.

39. Náque estágueando(hueveando) con el ratón, el ratón lo mataron to ahí, dello fue la culpa, no fue ratón,

40. ya se iba pabajo dos canoa parese, asi que se terminaron to ahí.

41. Entonse parese que yo me cuerdo que salió porotro lao el ratón se fue y su mamá quearon ahí, queó su mamá, queó su hermeno, igual queó junto, ya queó los tre ahí, lo que está solo,

42. parese que no molestó má elotro igual, dejó guear (huevear) no molestaron má, ya terminó morir elotro que venía;

43. ese cuento que venía porahí por San Pedro porahi, tenía eso kawésqar antiguo por allá pabajo, ahí terminó.

El cuento del ratón es posiblemente del que más versiones podemos encontrar. En este caso, por los lugares citados ("Trinidad" y "San Pedro"), la trama narrativa discurre de manera imprecisa entre dos polos bastante distantes entre sí, como son el canal Trinidad (al sur) y la zona del faro de San Pedro (al norte) ${ }^{13}$.

El ratón siempre fue persona, pero podía transformarse en ese animal cuando lo necesitaba para utilizar sus características (velocidad, pequeño tamaño, sigilo, etc.) y defenderse así de sus atacantes. El hecho de quedarse solo y abandonado, da la impresión que ocurre como consecuencia de la invasión de alguien, de gente mala que llega al lugar donde estaba con su familia ${ }^{14}$. Sea como sea, lo que aparece con claridad son las numerosas habilidades que desarrolla para sobrevivir durante años en soledad: correr con rapidez, saltar alto y lejos, lanzar piedras, navegar, esconderse; así como construir refugios, fabricar lanzas, mariscar o cazar mamíferos marinos.

La gente mala a la que hace referencia acaba con la vida de miembros varones de su familia (su padre y su tío, entre otros), pero pasado el tiempo, al encontrarse de nuevo con los agresores, las habilidades y destrezas desarrolladas son suficientes

miembros varones de su familia y se llevan a la madre Antes de que mataran a su hijo, la madre lo oculta debajo de una concha de cholga y así se salva. El lugar donde quedó solo lo identifican en el extremo sur de la isla Wellington, y el cerro al que se hace referencia se encuentra al norte del estero de Nuestra Señora, visible desde el canal Trinidad y desde el Brazo Norte. 
para hacerles frente con decisión y matarlos a todos. Circunstancia que le permite seguidamente el reencuentro con su mamá, que se había salvado, y su hermano ${ }^{15}$, para vivir tranquilos todos juntos, sin ser molestados a partir de entonces.

Cuento que relata una serie de acontecimientos marcados por el abandono, la desconfianza, la agresión y la valentía, así como por la necesidad de aprender ciertas técnicas de subsistencia y el apego a la familia. El peligro que supone ser atacado por algún grupo hostil en cualquier momento exige mantenerse siempre alerta, ser cauto y desconfiar de todo, circunstancia que puede evocar las tensiones territoriales que en dicha región existían entre las poblaciones canoeras. La lucha a muerte entablada aquí podría ser interpretada con motivo de esas tensiones territoriales o bien por el posible rapto de mujeres. En este relato mataron a los miembros masculinos de la familia del ratón (su padre, su tío, ...), y, aunque no se deja ver claro que la madre fuera raptada por el grupo agresor, si así fuera, como aparece en la versión registrada por Aguilera y Tonko (2010-2011a), teniendo en cuenta la existencia de exogamia entre los kawésqar, la decisión de matar por capturar mujeres quedaría motivada. Por otro lado, la eventualidad de sufrir un abandono por causas inesperadas, como es el caso, obliga a no perder el tiempo con lamentaciones; en la narración no aparecen muestras en ese sentido, más bien se trata de aprovecharlo para hacerse cargo de la nueva situación, aprender rápido y desarrollar todo lo necesario para sobrevivir en un entorno que no permite demasiados errores. La fuerza atractiva y emotiva de la familia aparece igualmente reflejada, se añora poder rehacerla en lo que quede de ella o se aspira a reconstituirla de nuevo como espacio de estabilidad y confianza donde procurarse una vida mejor. Circunstancia que está en sintonía con lo que sabemos sobre el modo de vida canoero y nómada practicado por los kawésqar en el pasado, en donde la familia nuclear independiente era el eje de la vida social y económica. La idea del héroe encarnada en el ratón-persona queda sin

15 En la versión registrada por Aguilera \& Tonko (20102011a), después de que el ratón ha dado muerte a cada grupo de Sæelam que trata de matarlo, su madre con su marido Sælam y su hijo, hermanastro del ratón, van desde el norte al sur a tratar de que acabe el conflicto entre el duda presente también en el cuento, como bien ha sabido explicar Brito en su exhaustivo análisis donde concluye: [...]importancia del héroe, del líder que impone un modelo cultural para que la comunidad oriente de modo pacífico ${ }^{16} \mathrm{su}$ vida sobre los mares procelosos del sur de Chile (Brito, 2012, p. 106).

\section{PERSONAS}

Kecheskula (relato de viaje y mítico)

1. Una persona que lo rompió su canoa un paraero lobo payá fuera,

2. andaba con su hermano los do, los do hermano que andaban, el resto su mujer quearon a tierra to eso,

3. anda traiendo dos chica elotro su hermano, a puro mujer a tierra hasiendo carpa.

4. No sé que tiempo e, poniendo huevo, primavera parese que fue, a buscar huevo de pájaro, poreso salió.

5. Esa canoa que perdió su canoa parese que no hablaba, hablaba pasito (despacito);

6. dise que a su hermano que vamo buscar huevo pájaro porahi;

7. "ellas que hagan carpa porque estamos gueveando";

8. dijo: "bueno, hoy día estamo gueveando (hueveando) aquí to, vamo salir buscar algo siquiera pa comer";

9. claro, su hermano igual, claro, "vámono, qué estamo hasiendo acá; to gueveando acá enun solo lugar, uno puesto buscando algo pa comer en la tarde noche siquiera".

10. ¡Puta!, salió ajuera (afuera) porahi serca había otro paraero lobo fino, paraero, sería parisión paraero dise que era, era un sitio grande con peasito monte igual;

11. entonse se fue pa juera al tiro, "entonse vamo mirá lobo fino si quiera;

ratón y los Sæelam, lo cual resulta exitoso.

16 En este relato el ratón no encarna un ideal pacífico, cuando mata a todos al verse amenazado por extraños, pero sí un comportamiento heroico al superar situaciones de abandono y adversidad (Brito, 2012, p. 93). 
vamo, vamono, aprovechemo ese calma que está, vamos acá unos cuanto lobito chico, ahí vamo a tierra al tiro";

12. ená que se queó ahí mismo la isla, a tierra su canoa lo varó ahí a tierra, empesó sacar pita ahí.

13. Su hermano se queó pensando: “¿qué estará hasiendo éste?", pensaba pa volver a tierra no está hasiendo carpa, igual lo molestaba, igual estaba hasiendo carpa, hay que dejar bien arriba la canoa,

14. despue dise que le faltó su leña, lotro día lo hiso peaso [sonríe], claro, se queó sin canoa;

15. ya su hermano estaba asustao, claro había hecho peaso la canoa, qué va haser ahora pa quear, y no hay agua tampoco, puro piedra pilao ni una cosa, y mataron lobito lo hiso asao, y ahora dónde está agua pa tomar, na.

16. Claro que jodió ya, lo hiso peaso la canoa, to lo echó al juego (fuego).

17. Despué dise que lo retó su hermano: "oye ¿pa qué lo está hasiendo peaso canoa?, ere un hombre viejo que está gueveando igual que un cabro chico, peor que un cabro chico, to lo dejamo a tierra botao, ahora qué cosa vamo comer si no tiene canoa tampoco pa mariscar, qué cosa".

18. Dijeron: "estate tranquilo, no má callao, dise que desía esotro".

19. Ese hombre dise que tiene poder igual, esa noche como a las dié, las dose la noche porahi, dise que dijeron, "salió vamo balsamar";

20. elotro está escuchando ahí, ahora que rompió su canoa va balsamar turón, [sonríe] eso ese hombre pensaba, ahora cómo lo qué forma va haser canoa, ahi hay dos turones, un canoa ca uno va haser, eso tenía que matale su canoa, ese turone grande ca uno tiene que matar, claro, pa haser canoa.

21. A lotro día se levantó emprano anda mirar abajo si hay turó lo mata despué se quea conuna cosa ahi, claro, ahí estaba durmiendo ahi, donde estaba sentao anoche; "alomejor porahi hay algo, anda buscar".
22. "Tengo sed", desía elotro, claro, porahi hay linda posita de agua; claro, se paresieron to ahi, claro que linda posa de agua, igual que una cuestión se llena prontito.

23. Lo mataron lobo fino, lo sacó cuero, cuero lobo fino questaba hasiendo, no se lo compraron, pareció lotrobicho;

24. de repente estaba hasiendo canoa, que lindo canoa; "éste cómo le será parese", lo pensaba su hermano, "algún suerte tendrá".

25. Y ese mismo dijo que iban remolcar to ese tiburone que anda to eso, alguno vana remolcar pa tierra, vana dejar; claro que fue sierto, lo marró su laso cogote, lo marró el canoista, los do canoa, uno ca uno su remolcaor;

26. hay que levantar al paso el tiburón de lobo fino que anda, pa que no lo eche pique eso canoista el cuero, y ya a tierra lo dejaron ahi;

27. ella lo volvió pa paraje de lobo fino, los do, el resto eso chiquitito que vinieron to eso queó ahí la playa flotando como muerto quearon to ahí; elotro empesó recoger pa guardá to eso. Ese cuento era lindo.

28. Este cuento es de cerca Natales.

En el relato de Kecheskula (nombre de persona), situado en torno a Puerto Natales, en tiempo de primavera, dos hermanos dejaron a sus mujeres en la costa haciendo la carpa, mientras ellos decidieron salir con la canoa a buscar huevos de aves o algo para comer. Durante el trayecto por mar pasaron junto a una lobera y decidieron varar allí la canoa para capturar popis (crías de lobos marinos). Con la canoa varada tierra adentro uno de los hermanos hizo carpa para pernoctar y al faltarle leña para el fuego usó la de la embarcación, destrozándola.

El otro hermano se enojó al darse cuenta que su hermano había destrozado la canoa y no tenían medios para cazar y mariscar. Sin poder salir de allí mataron lobitos para comer, pero no había agua potable ni vegetación, era puro roquedal. El que rompió la canoa (que entendemos es Kecheskula) trataba de tranquilizar a su hermano diciéndole 
que no se preocupara porque tenía poderes. Y en efecto, a la mañana siguiente le mostró una poza de agua para beber, fabricando también dos canoas con la piel de dos toronos (lobos machos adultos) a los que dieron muerte. Solucionado el problema de transporte, con ambas canoas remolcaron sus capturas de lobo fino hasta tierra y regresaron a la lobera a capturar más. Así concluye la narración, aunque este cuento aparece registrado como "Cuento del náufrago", T-PE_289207=7, inédito, en Aguilera y Tonko (2010-2011b) Corpus de Cuentos Kawésqar. Documento de CONICYT, y es mucho más extenso que el fragmento que se ofrece aquí. Consta de 195 segmentos y éste solo contiene 28. ${ }^{17}$

Relato lleno de sorpresas, en donde queda de manifiesto que nada está asegurado. El infortunio puede aparecer cuando menos se espere, así como las rachas de buena suerte y prosperidad. No obstante, la perseverancia y el esfuerzo compartido en el trabajo, junto con la esperanza, que se puede deducir de las dotes mágicas de uno de los hermanos (Kecheskula), son, visto desde fuera, destacados valores desprendidos del relato. Este cuento, parcialmente recogido aquí, se ajusta a la estructura de relato de viaje (Aguilera, 2011a), en cuanto que posee un punto de partida, un recorrido con puntos intermedios de llegada y un punto de llegada final, en su versión completa en kawésqar; también en la caracterización de los personajes y trama de acontecimientos; aunque, desde este último punto de vista, cuenta igualmente con aspectos propios del relato mitológico por los

17 La versión completa del relato en kawésqar da más detalles de la historia, el hermano mayor que destroza la canoa exhibe poderes de predicción. Igualmente está el evento de la destrucción de la canoa y la construcción posterior de una canoa de cuero de lobo, pero son remolcados por un lobo. Al llegar a tierra encuentran una carpa ceremonial (čeló) con una fogata encendida. Allí asan la carne que trajeron y comen. El hermano mayor predice la aparición de una canoa de madera que se encuentra invisible y con esa se irían a su campamento donde los esperaba su familia. Efectivamente la canoa se hace visible y los hombres parten y se reúnen con los suyos. El cuento en el corpus completo, además de la perseverancia, enfatiza el don que posee el hermano mayor de predecir el futuro y lo desconocido, como lo misterioso y fantástico de la aparición de una canoa con todos sus aparejos y viveres. En el relato kawésqar no aparece el nombre del hermano mayor. La poderes de predicción manifestados en uno de los hermanos.

Enfrentamiento y Ayuda mutua (relato de viaje)

1. Eso que había por allá arriba; dise quesenoja por paraje lobo.

2. Eso pelear lo hasía a rato no má, no era mucho; asi no hase ni una cosa hasta que se terminó pelear, ahí dise que contó ahí mismo que peleó donde estaba su carpa ahi mismo;

3. ahí dise que se peleó por su carne lobo cosío (cocido), lapa, to eso pa comer;

4. está to contento ello despué [sonríe], ese me contaba ese cuento y escuchando nosotro, me gustaba nosotro.

5. Ante nunca se nojaba, se nojaba al rato questá pasao ya no sacuerda má.

6. Dise questá llegando del puerto donde está lojao elotro, lotro había llegao primero, había lojao, unos sinco, sei;

7. despué dise que lo preguntaba, tiene que haber lobo ahi, claro, to el tiempo estarian ahi, po nunca ha andao mucho, solo cuando se calma mar salía buscar lobo, si levanta mar nosotro no salimo,

8. mañana si está bueno vamo mirar si hay lobito, claro, mañana, según que manesca bueno;

9. ahí dise que no no molestaba má, pasa junto to un me o do mese están ahi, "iputa!, junto despué sale";

10. dise que sencontraba y allí

versión completa del relato en kawésqar da más detalles de la historia, el hermano mayor que destroza la canoa exhibe poderes de predicción. Igualmente está el evento de la destrucción de la canoa y la construcción posterior de una canoa de cuero de lobo, pero son remolcados por un lobo. Al llegar a tierra encuentran una carpa ceremonial (čeló) con una fogata encendida. Allí asan la carne que trajeron y comen. El hermano mayor predice la aparición de una canoa de madera que se encuentra invisible y con esa se irían a su campamento donde los esperaba su familia. Efectivamente la canoa se hace visible y los hombres parten y se reúnen con los suyos. El cuento en el corpus completo, además de la perseverancia, enfatiza el don que posee el hermano mayor de predecir el futuro y lo desconocido, como lo misterioso y fantástico de la aparición de una canoa con todos sus aparejos y víveres. En el relato kawésqar no aparece el nombre del hermano mayor. 
peleaba [sonríe], dise que quebraba su vara pa lobo, ese vara es que quebraba, lo cortaba con hacha al fuego no má, to y ahí tenía que buscar otro en la tarde o lotro día, conese ya no molesta má eso;

11. ya se agarraba lobo dise que lo rompía to ahi cosio; tiene que comer to junto, to eso questá carpa pa yá, to eso lejo, uno se va repartir a cabro chico, cabro no tan chico, cabro con 14, 15 año, ese tenía que repartir peaso carne lobo, ante no come solo, tiene que comer to junto, si tenía ello algo tenía que repartir, to lo mismo;

12. (...) no le dá ná, prefería que lotro está mirando y lotro está comiendo, [tose] tenía su costumbre ello, hay que comer to junto, si no tiene otra cosa come na má to, to lo mismo; to pa comer, aunque sea poco igual lo reparte poquito.

13. Ahoa no, ahora estamo costumbrao como huilliche, solo aqui, aunque esté muriendo aquí al lao de la casa, como acá al lao está comiendo bien uno, ante no, ante había costumbre deso, el mayor lo repartía to pa comer.

Este relato no cuenta con un personaje principal y por su brevedad tal vez sea una parte de un relato mayor. En cualquier caso, refiere que en el pasado los enojos duraban poco tiempo y cuando sucedía algún conflicto al poco se olvidaba. La rivalidad por las loberas para cazar, la disputa por conseguir la carne de lobo o de lapa cocida para comer, o el hecho de comprobar que de manera intencionada se ha quebrado la vara del arpón de alguien para impedirle salir de caza, son citados como comportamientos que motivan enfados y peleas pasajeras.

Sin embargo, lo que predominaba era la cordialidad mientras permanecían reunidos durante uno o dos meses seguidos, planeando quiénes quedan en el campamento y quiénes salen a cazar lobos marinos. Eso sí, con la precaución de partir al amanecer siempre que el buen tiempo acompañe y la mar esté en calma.

Al regreso los antiguos repartían por igual las capturas, el mayor era responsable del reparto, y no consentían que nadie mirara mientras otros comían, a diferencia de lo que, según dice, ocurre en la actualidad que acostumbrados a hacer como los huilliches, ni los vecinos te prestan atención aunque te estés muriendo junto a la casa. Describe lo que Emperaire (1963, p. 229) reconoce como tchas o práctica de intercambio de alimentos y utensilios entre las familias que eventualmente componen un grupo mayor; práctica que en el entorno de Puerto Edén es vestigio de una institución mucho más importante en otro tiempo, basada en la generosidad y reciprocidad como medida solidaria para garantizar una mayor seguridad social. Dicha práctica podía ser colectiva (entre familias) o individual (entre personas). Denominada también t'cas o c'as (Aguilera, 2007).

Como comentario final, el narrador llama la atención sobre el comportamiento solidario de los antepasados, en el que todos colaboraban y todo se repartía para el mutuo beneficio, especialmente en momentos difíciles; echándolo en falta en la actualidad.

\section{CONSTANTES DEL IMAGINARIO Y VALORES KAWÉSQAR}

La moraleja, como consecuencia del tipo de cuento, bien sea un relato mítico o un relato de viaje, posee un carácter generalmente aleccionador, enseña, llama la atención sobre algún asunto importante en la vida de las personas, o bien procura hacer entendible algún hecho o acontecimiento remoto del que es preciso informar para salir de dudas o tener una opinión formada.

Como acabamos de ver, la muestra de seis cuentos pertenecientes a los tres grupos narrados por D. Francisco Arroyo, localizados espacialmente por distintos puntos del archipiélago patagónico (Fig. 1), trata un buen número de aspectos que van en la dirección de enseñar y hacer comprender el pasado y el presente a través de historias repletas de ingenio y sentido. Los temas que de manera regular aparecen en mayor o menor grado en los distintos cuentos (en los seis aquí transcritos y en los 22 que forman el corpus total de nuestro trabajo), ofrecen un interesante panorama de actitudes y comportamientos ante diversas situaciones de la vida, que nos aproxima al menos al sistema de valores culturales kawésqar. En tal sentido, de las transcripciones presentadas, desde una óptica 
externa y con las debidas reservas, podemos destacar lo que sigue a continuación:

1. Uno de los más repetidos trata la "desconfianza" manifestada por los protagonistas de las acciones en cada caso, y la "prudencia" con la cual desenvolverse para seguir vivo. La mujer sol desconfía subir al cielo cuando aún era un territorio desconocido, el humanizado ratón ha de mantenerse siempre vigilante para evitar ser asaltado. Desconfianza justificada en la medida que la mayoría de las historias están llenas de intriga, incertidumbre, $e$ incluso conspiraciones y traiciones.

2. La idea de la "muerte sorpresiva", bien por accidente o por asesinato, está muy presente en los relatos. Ligado con ello se encuentra la "incertidumbre" ante los imponderables de la vida cotidiana, el pensamiento de que nada está nunca del todo asegurado, y que mucho tiene que ver con la navegación, con la pérdida de la canoa por algún motivo. Son distintas las circunstancias que inducen a morir a los personajes, lo cual corrobora la tipología que sobre la muerte en los relatos míticos señalan Aguilera y Tonko (2009, pp. 14-15): rompimiento de tabú, engaño, venganza, criaturas monstruosas, conflicto entre grupos antagonistas, o por diversas causas.

3. Es por ello que la "búsqueda de tranquilidad", así como la "reunión con los seres queridos", ante tanta separación que muchas veces se presenta inevitable, constituyen una aspiración permanente en los relatos. Aunque sin perder el "espíritu viajero", el cambio de lugar al encuentro de renovados horizontes, que también lo tenemos como constante.

4. Los "alimentos" aparecen de igual modo como un valor esencial. Es la comida un estímulo fundamental para que la sol, la luna y las estrellas se queden finalmente arriba; un elemento de referencia que mueve a la acción en casi todos los relatos.

5. Otro tema destacado es relativo a las "transformaciones" o metamorfosis

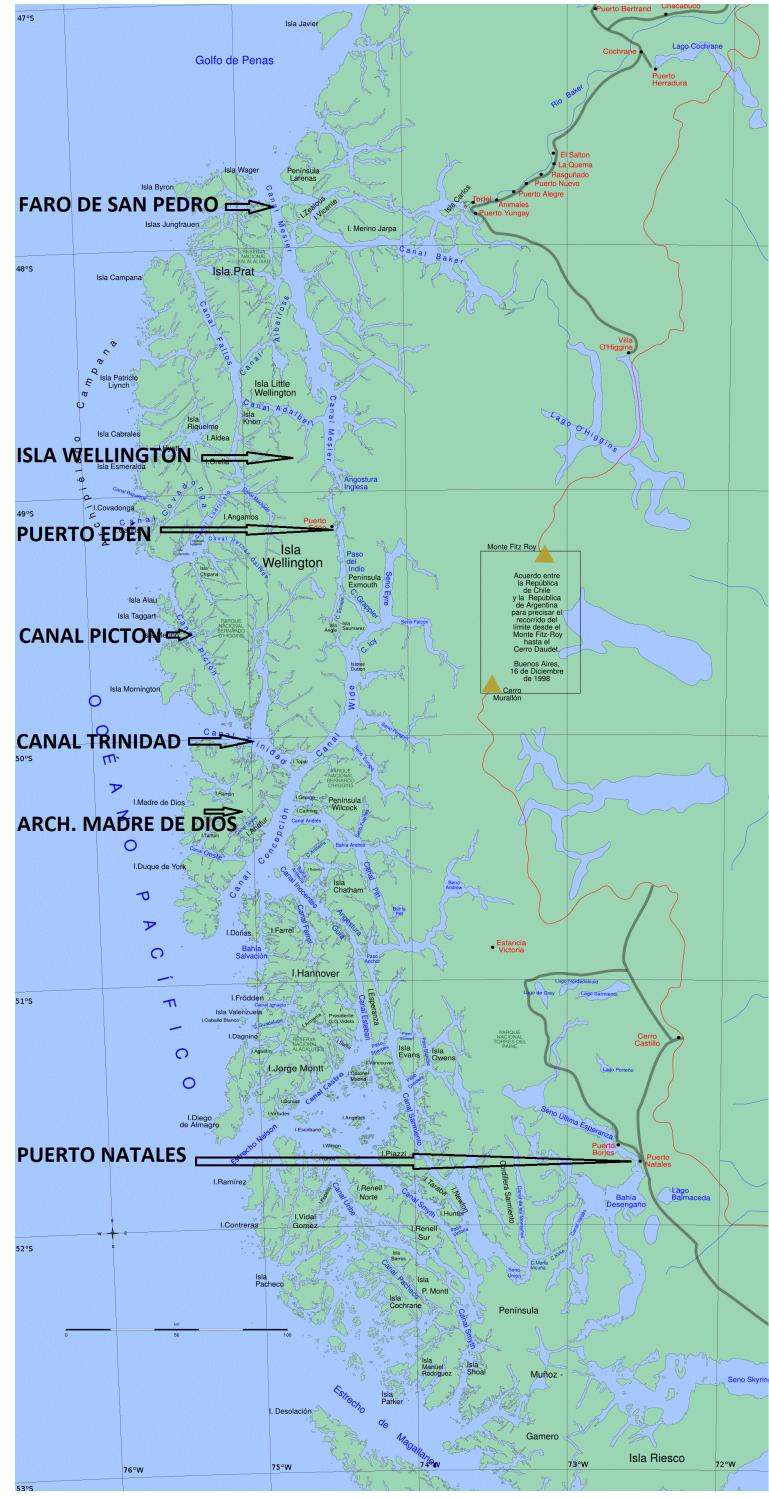

Fig, 1. Mapa del archipiélago patagónico chileno, con localización de lugares mencionados en los relatos. Fuente: Google. Elaboración propia.

que se producen de personas convertidas en astros (sol, luna, estrellas), en accidentes geográficos (piedras, cerros, puntilla) o en animales (ratón, sapo, pájaros, nutrias, coipos) $)^{18}$; lo cual se produce habitualmente como consecuencia de una acción que puede beneficiar o perjudicar a quien la ejecuta. La conversión en astros da la impresión de 
implicar un aumento de poder por parte de quien la experimenta, al observarlo todo desde arriba; mientras que la metamorfosis en accidentes geográficos implica más bien la idea de inmovilizar al protagonista de la acción; aunque en ambos casos queda patente la perdurabilidad, el hecho de hacerse eterno. También es significativa la estrecha vinculación de las personas y los animales ${ }^{19}$.

6. "Aleccionar sobre lo que se estima adecuado" está también muy presente de distintos modos ${ }^{20}$. La ayuda al prójimo e incluso la caridad es un valor destacado en los relatos ${ }^{21}$; así como el tesón, la perseverancia para conseguir lo deseado o salir de apuros. Es el apoyo mutuo, sobre todo centrado en la unidad familiar, la clave por la que se consigue en muchos casos sobrevivir, y ello no está en contradicción con el pretendido aislamiento que en ocasiones es deseable para evitar problemas.

7. Encontramos una cierta tendencia a valorar el comportamiento de los antepasados $e$ incluso las condiciones ambientales de épocas remotas, de manera más positiva que los situados en el presente. Los cambios en algunos casos no son considerados satisfactorios, añorándose el tiempo o la época en que las condiciones de vida en común y con el entorno eran mejores. Pese a todo y lejos del derrotismo o la rendición ante la adversidad, el "instinto de supervivencia" impregna posiblemente la mayor parte de las historias relatadas.

8. La explicación de los "orígenes de ciertos fenómenos naturales" no abunda, pero la encontramos al menos en relación

19 En el cuento del Lobo marino (no transcrito aquí), éste convive y procrea con la mujer kawésqar, dándose a entender que todos forman parte de una misma esencia o unidad, que son seres naturalmente intercambiables. Como señala Lèvy Bruhl (1974), en relación a la mentalidad primitiva: siente instintivamente la homogeneidad de esencia de todos los seres y no da casi importancia a su forma exterior (p. 26).

20 De manera explícita en el cuento de la Tormenta y la Noche (no transcrito aquí) se habla sobre por qué hay que varar la canoa y hacer la carpa antes de que caiga el sol, y la conveniencia de salir a remar poco antes de amanecer. Y de forma implícita, con el fuego (que trae el huemul) y con el viento (provocado por una persona que sopla introducida en la orilla del mar).

9. Sobre el "fuego", no obstante, al igual que sobre los alimentos, se insiste mucho (en el corpus total de 22 cuentos) en constatarlo como un recurso imprescindible para la supervivencia.

10. Y, cómo no, las "homologías", las asociaciones de determinados hechos que entre sí transmiten un mensaje, podemos apreciarlas en pasajes como el atardecer ligado al momento que la mujer sol sube al cielo con sus hijas las estrellas ${ }^{22}$.

En definitiva, aparte de servir para entretener a quienes lo escuchen de boca de un gran especialista como D. Francisco Arroyo, el conjunto de cuentos kawésqar por él narrado desempeña una función claramente informativa y transmisora de un conocimiento tradicional que, por lejano que resulte en muchos aspectos, puede permanecer vivo en la memoria formando parte del patrimonio cultural intangible desarrollado por las pasadas generaciones, y ofrece claves que ayudan a entender mejor el sistema de valores e identidad kawésqar.

\section{BIBLIOGRAFÍA}

Aguilera, N. (2013). Pueblos Indígenas en Magallanes, perspectivas en el Siglo XXI. En J. Durston (Coord.) Pueblos Originarios y Sociedad Nacional en Chile: la interculturalidad en las prácticas sociales (pp. 160180). Santiago de Chile: PNUD, Fondo para el logro de los ODM.

Aguilera, O. (1995). Cuento de los astros (MEG)T-PE-071=4, narrado por José López. Corpus de Cuentos Kawésqar.

en el cuento de los Perros (tampoco transcrito aquí) se induce a seguir el ejemplo de quien obra con laboriosidad y solidaridad y a evitar a quien actúa como vago, desobediente y mezquino. Por otro lado, las consecuencias sobre la violación de un tabú o sobre actos indebidos son también apreciables en varios relatos del corpus total de 22 cuentos.

21 La reciprocidad es un principio habitual en los pueblos amerindios.

22 En otros cuentos no transcritos aquí, aparecen también homologías entre el rayo ligado con la idea de la muerte; al igual que la tormenta y la noche con la inactividad, la incertidumbre y el peligro. 
Documento de Trabajo.

Aguilera, O. (1997). La expresión del tiempo en Kawésqar. Onomazein, 2, 169-304.

Aguilera, O. (2001). Gramática de la Lengua Kawésqar. Temuco: Corporación Nacional de Desarrollo Indígena.

Aguilera, O. (2007). Lenguas y culturas de Chile. Kawésqar. http://www.kawesqar.uchile.cl/cultura/index.html

Aguilera, O. (2011a). Los relatos de viaje kawésqar, su estructura y referencia de personas. Magallania, 39(1), 119-145.

Aguilera, O. (2011b). Cuento de Annápas. (T-PE-27027=1). Documento de trabajo. Proyecto FONDECYT No. 1100334. MS.

Aguilera, O. (2013). El arte de la palabra en los canales patagónicos. La literatura oral kawésqar. Punta Arenas: La Prensa Austral Impresos.

Aguilera, O. (2016). Habitar en el espacio y el lenguaje; el léxico de la geografía Kawésqar. Magallania, 44(1), 85-101.

Aguilera, O. (2017). El nombre Kawésqar, un problema no solo lingüístico. Magallania, 45(1), 75-84.

Aguilera, O., \& Brito, M. E. (1980). Análisis de un texto kawésqar, Boletín de Filología, XXXI, 303-329.

Aguilera, O., \& Tonko, J. (2017). Colección de Cuentos Kawésqar Para la Educación Básica y Media. Literatura Oral Kawésqar. Punta Arenas: CONADI.

Aguilera, O., \& Tonko, J. (2013). Cuento de los astros. T-SA$171006=2 e$, narrado por Francisco Arroyo. Corpus de Cuentos Kawésqar. Documento de CONICYT.

Aguilera, O., \& Tonko, J. (2010-2011a). Cuento del Ratón. (T-PE-240407=1a \& 1b). Documento de trabajo. Santiago de Chile: Proyecto FONDECYT No. 1100334. MS.

Aguilera, O., \& Tonko, J. (2010-2011b). Cuento del náufrago. (T-PE_289207=7). Corpus de Cuentos Kawésqar. Documento de CONICYT.

Aguilera, O., \& Tonko, J. (2009). Cuentos Kawésqar. Santiago de Chile: Fundación de Comunicaciones, Capacitación y Cultura del Agro, FUCOA. Ministerio de Agricultura; Programa Orígenes, Corporación Nacional de Desarrollo Indígena (CONADI).

Aguilera, O., \& Tonko, J. (2006). Literatura oral kawésqar: cuento del Pájaro Carpintero y su esposa, la Mujer Tiuque; Primera Parte. Onomazein, 14(2), 9-63.
Aguilera, O., \& Tonko, J. (2005). Diccionario conciso Español - Kawésqar. Punta Arenas: Fundación para el Desarrollo de Magallanes FIDE XII, Corporación Nacional de Desarrollo Indígena.

Brito, E. (2012). Tres héroes del mundo mítico kawésqar. Magallania, 40(1), 93-107.

Casson, R. (1983). Schemata in Cognitive Anthropology. Annual Review of Anthropology, 12, 429-462.

Eco, U. (1977). Tratado de semiótica general. Barcelona: Lumen.

Emperaire, J. 1963. Los nómades del mar. Santiago de Chile: Ediciones de la Universidad de Chile.

Finnegan, R. (1970). Oral Literature in Africa. Oxford: Clarendon Press

Gusinde, M. (1991 [1974]). Los Indios de Tierra del Fuego. Tomo III (1 y 2) (Los Halakwulup). Buenos Aires: Centro Argentino de Etnología Americana.

Hauser, M. D. (2008). La mente moral. Barcelona: Paidós.

Hocart, A. M. (1985 [1969]). Mito, ritual y costumbre. Ensayos heterodoxos. Madrid: Siglo XXI.

Hymes, D. (1962). The Ethnography of Speaking. En T. Gladwin \& W. C. Sturtevant (Eds.), Anthropology and Human Behavior (pp. 13-53). Washington: The Anthropology Society of Washington.

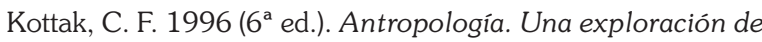
la diversidad humana. Madrid: McGraw-Hill.

Kristeva, J. (1978). Semiótica. Vol. 1 y 2. Madrid: Fundamentos.

Lèvy Bruhl, L. (1974). El alma primitiva. Barcelona: Ediciones Península.

Lèvi-Strauss, C. (1987). Mito y significado. Madrid: Alianza Editorial.

Martinic, M. (2004). Archipiélago Patagónico, la última frontera. Punta Arenas: Ediciones Universidad de Magallanes.

Ong, W. J. (1982). Oralidad y escritura. Tecnología de la palabra. México: Fondo de Cultura Económica.

Propp, V. (1985 [1928]). Morfología del cuento. Madrid: Akal.

Schwartz, F. (2008). Mitos, ritos, símbolos. Antropología de lo sagrado. Buenos Aires: Editorial Biblos.

Tedlock, D. (1983). The spoken word and the work of interpretation. Philadelphia: University of Pennsylvania.

Todorov, T. (1978). Symbolisme et interpretation. Paris: Seuil. 